\title{
Het begeleiden van studenten met tekortkomingen op het gebied van professioneel gedrag
}

\author{
S.J. van Luijk, M.L.F. Perquin, G. Tans
}

\section{Samenvatting}

Inleiding: Professioneel gedrag is steeds vaker onderdeel van de geneeskundestudie. Dit vereist begeleiding van studenten met problemen op dit gebied. Professioneel gedrag omvat: omgaan met taken/werk, met anderen en met zichzelf. Begeleiding kan geboden worden binnen de bestaande voorzieningen voor studentenbegeleiding.

Studenten met tekortkomingen op het gebied van professioneel gedrag: In de literatuur worden als specifieke problemen genoemd: gebrek aan verantwoordelijkheidsgevoel, niet nakomen van afspraken, gebrek aan initiatief, gebrek aan samenwerking, niet kunnen omgaan met kritiek en niet kunnen communiceren met patiënten. Studenten met problemen kunnen vaak niet goed reflecteren op het eigen gedrag. Doorgaans zijn er ook problemen betreffende kennis en vaardigheden. Vroege opsporing kan een effectieve aanpak bevorderen.

Omgaan met problematiek van studenten met onprofessioneel gedrag: De studiebegeleider kan het probleem zelf aanpakken, maar ook hulp binnen en buiten de universiteit inschakelen. Coördinatie door één persoon is belangrijk.

Specifieke aandachtspunten bij de begeleiding: Duidelijkheid over de verantwoordelijkheid voor de begeleiding. Het tijdstip waarop tijdens de studie begeleiding gegeven wordt, bepaalt de vorm ervan. Een zorgvuldige dossieropbouw is belangrijk.

Ten slotte: Faculteiten moeten zich voorbereiden op een groter aanbod van studenten die op enigerlei wijze disfunctioneren in het onderwijs. De aanpak hiervan vereist een goed protocol van begeleiding en verwijzing. Afstemming in een vroeg stadium van mogelijkheden en beperkingen van ieders rol en deskundigheid binnen en buiten de faculteit zal onnodige vertraging in het aanbod van zorg naar de student zoveel mogelijk voorkomen. (Luijk SJ van, Perquin MLF, Tans G. Het begeleiden van studenten met tekortkomingen op het gebied van professioneel gedrag. Tijdschrift voor Medisch Onderwijs 2002;21(5):228-235.)

\section{Inleiding}

Het bespreken en beoordelen van professioneel gedrag als onderdeel van de voorbereiding op de latere beroepsbeoefening staat in toenemende mate in de belangstelling binnen de medische faculteiten in en buiten Nederland. Professioneel gedrag krijgt ook ruim aandacht in het onlangs verschenen eindrapport van het Projectteam Consilium Abeundi, waarin ook delen van dit artikel zijn opgenomen. ${ }^{1}$ Minder duidelijk is hoe moet worden omgegaan met studenten die op de een of andere wijze tekortschieten op onderdelen van het professionele gedrag. Met welke aspecten van onprofessioneel handelen de begeleider van de student wordt geconfronteerd en welke remediërende mogelijkheden er zijn, hangt sterk af van de implementatie en uitwerking van het onderwijs en de wijze waarop de beoordeling van professioneel gedrag in het curriculum is ingepast.

Aan de medische faculteit in Maastricht bestaat een studiebegeleidingssysteem dat openstaat voor alle studenten van alle jaargroepen. Ook vragen en problemen met betrekking tot professioneel gedrag wor- 
den binnen dit studiebegeleidingssysteem behandeld. Het begeleiden van studenten met tekortkomingen op het gebied van professioneel gedrag verschilt niet wezenlijk van het begeleiden van studenten met tekortkomingen op andere gebieden. Centrale elementen in het begeleidingsproces zijn: definiëring van het probleem, het maken en vastleggen van duidelijke afspraken om de problemen te lijf te gaan en het houden van contact met de student gedurende de tijd dat het probleem speelt. Bij problematiek rondom professioneel gedrag zullen bepaalde onderdelen van het begeleidingsproces meer nadruk krijgen. In het algemeen zal de studieadviseur studenten met problemen op het gebied van professioneel gedrag vaker oproepen gedurende een langere periode. Per gesprek zal meer tijd nodig zijn dan voor de reguliere student. Bovendien zal er vaker een beroep worden gedaan op andere hulpverleners (huisarts, psycholoog, studentendecaan).

In dit artikel wordt ingegaan op de begeleiding van studenten met deze problematiek. Aandacht wordt besteed aan bestaande modellen van studiebegeleiding om daarmee het kader te schetsen waarbinnen de begeleiding wordt aangeboden. Vervolgens komen aan bod, de aard van de problematiek, de verschillende vormen van ondersteuning die kunnen worden aangeboden en specifieke aandachtspunten bij de begeleiding van deze groep studenten. Eerst wordt kort beschreven wat verstaan wordt onder professioneel gedrag.

\section{Wat is professioneel gedrag?}

Professioneel gedrag wordt omschreven als al het observeerbare gedrag waarin normen en waarden van de beroepsbeoefening naar voren komen. ${ }^{2}$ Binnen dit gedrag worden drie dimensies onderscheiden, namelijk omgaan met taken/werk, omgaan met anderen en omgaan met zichzelf. ${ }^{3}$ Omgaan met taken/werk betreft gedrag dat te maken heeft met het zich houden aan afspraken, bijhouden van het vakgebied, inzet, terugrapportage, eigen grenzen kunnen bepalen, delegeren, et cetera. Omgaan met anderen betreft de communicatie en samenwerking met patiënten, staf en collega-studenten. Hierbij gaat het bijvoorbeeld om specifieke communicatieve vaardigheden en het kunnen onderhandelen. Omgaan met zichzelf heeft te maken met het vermogen kritisch naar zichzelf te kijken (kunnen reflecteren), openstaan voor kritiek en het kunnen omgaan met feedback.

\section{Modellen voor het begeleiden van studenten}

Er bestaan twee modellen van studiebegeleiding aan de medische faculteiten in Nederland: een centrale vorm en een 'mengvorm' met centrale en decentrale begeleidingselementen. De centrale vorm van studiebegeleiding komt het meest voor. Deze houdt in dat één of meerdere specifiek daartoe aangestelde functionarissen - studieadviseurs of studiebegeleiders genoemd - aanspreekpunt zijn waar studenten terecht kunnen met vragen om informatie over het curriculum en de regelgeving, studieproblemen en problemen van persoonlijke aard en andere zaken betreffende onderwijs en toetsing waarvoor geen 'loket' beschikbaar is. Tevens vervullen de studieadviseurs een rol bij de terugkoppeling naar de faculteit van informatie over vragen en problemen van studenten met het onderwijs en de toetsing. Het betreft vrijwel uitsluitend medewerkers die zelf geen onderwijsrol binnen het curriculum vervullen. In het algemeen zijn deze functionarissen aanspreekbaar voor alle studenten van het hele curriculum. Wanneer er meerdere studieadviseurs per faculteit zijn, kan er 
worden afgesproken dat bepaalde studieadviseurs slechts bepaalde jaargroepen begeleiden.

De mengvorm bestaat uit een begeleidingsysteem met zowel mentoren als studieadviseurs, waarbij mentoren als het ware de eerstelijnszorg voor studenten op zich nemen en de studieadviseurs de tweedelijnszorg. Deze vorm komt sporadisch voor aan medische faculteiten, namelijk aan het UMC St. Radboud in Nijmegen en in het nieuwe curriculum van de Faculteit Geneeskunde in Maastricht.

De bestaande verschillen in vorm van studiebegeleiding zijn in zoverre relevant dat het binnen faculteiten voor studenten en medewerkers duidelijk moet zijn wie het eerste aanspreekpunt is voor studiebegeleiding betreffende professioneel gedrag. Is dat de studieadviseur, de mentor of een andere door de faculteit aan te wijzen functionaris, bijvoorbeeld een ervaren medisch practicus. Aangezien de problematiek bij professioneel gedrag in het algemeen complex van aard is, is het belangrijk dat één persoon verantwoordelijk is voor de coördinatie van de begeleiding. Deze functionaris dient ook inzage te hebben in het studiedossier met onder andere een overzicht van alle resultaten van de student. Om dit mogelijk te maken moet de positie van deze functionaris vastgelegd zijn in de Onderwijs- en Examenregeling (OER). Dit is vooral belangrijk omdat problemen met professioneel gedrag op meerdere fronten aandacht vragen. In ernstige gevallen is er in het dossier van de student vaker een patroon te herkennen van niet verschijnen bij onderwijs of examenmomenten en beperken tekortkomingen zich vaak niet alleen tot gedrag maar betreffen ook kennis en vaardigheden.

\section{De rol van de begeleider en de examencommissie}

De begeleider van de student dient zowel gesprekspartner te zijn voor de student als voor de onderwijsorganisatie. Met betrekking tot de student geldt dat meestal intensieve persoonlijke begeleiding nodig is die erop is gericht dat de student zich bewust wordt van het probleem. Ook dient de begeleider een rol te spelen bij het remediëren van tekortkomingen. Vaak spelen er ook problemen op het gebied van kennis en vaardigheden, persoonlijke problematiek en problemen rondom de studiefinanciering. De begeleider heeft een eigen verantwoordelijkheid inzake het te volgen beleid voor de oplossing van het probleem. De begeleider is dus niet bij voorbaat 'advocaat van de student', zoals wel eens wordt beweerd. Evenmin echter dient de begeleider kritiekloos de adviezen van de examencommissie te volgen. De examencommissie speelt een belangrijke rol bij deze problematiek vanuit het oogpunt van studievoortgang. De inbedding van de beoordeling van professioneel gedrag in het examenreglement is voor studenten die moeite hebben zich bewust te worden van hun probleem van essentieel belang. Soms helpt druk vanuit de examencommissie - door het stellen van voorwaarden of dreigen met sancties om de student ertoe te brengen hulp te zoeken voor gerezen problemen. Voor studenten die een goed inzicht hebben in hun zwakke punten en bereid zijn te veranderen is dat veel minder belangrijk.

De begeleiding is uiteraard het meest gediend met een goede afstemming tussen alle actoren die zich met de student bezig houden, met behoud van de eigen verantwoordelijkheid. De professionaliteit van de begeleider behelst onder meer het met elkaar in harmonie brengen van de vaak tegengestelde belangen van student en onderwijsorganisatie. 
Op dit moment lijkt op de meeste faculteiten de studieadviseur een belangrijke functionaris te zijn bij deze problematiek. Meestal vervult deze een coördinerende rol tussen de verschillende instanties en personen die zich binnen en buiten de faculteit met de desbetreffende groep studenten bezig houdt. Dit speelt des te meer wanneer er sprake is van een gemengde centraal/decentrale vorm van studiebegeleiding. Gemaakte afspraken dienen helder te zijn voor zowel docenten als studenten. In de praktijk blijkt dat de 'gewone' docent vaak niet weet hoe omgegaan moet worden met problemen ten aanzien van professioneel gedrag en aan wie dergelijk gedrag gemeld moet worden.

\section{Studenten met tekortkomingen op het gebied van professioneel gedrag}

Een systematische inventarisatie van de problemen die zich voordoen bij studenten met onvoldoende professioneel functioneren heeft binnen Nederland nog niet plaatsgevonden. Ook met betrekking tot achtergronden en oorzaken is nog weinig beschreven. De buitenlandse literatuur geeft hier wel enige informatie over. ${ }^{6}$ De tekortkomingen die beschreven worden betreffen met name een gebrek aan verantwoordelijkheidsgevoel, niet nakomen van afspraken, gebrek aan initiatief, gebrek aan samenwerking, niet kunnen omgaan met kritiek, niet kunnen communiceren met patiënten en presentatie (arrogant).

Binnen de verschillende faculteiten in Nederland is er wel sprake van incidentele casuïstiek, zeker betreffende ernstiger vormen van onprofessioneel gedrag. Voorzover ervaringen tussen faculteiten zijn uitgewisseld, blijkt dat de problemen vergelijkbaar zijn met wat in de literatuur beschreven wordt. ${ }^{1}$ Wat opvalt bij de groep studenten met ernstige tekortkomingen op het gebied van professioneel gedrag is dat deze niet kunnen reflecteren op eigen ge- drag. Waargenomen tekortkomingen in het functioneren binnen het onderwijs worden volgens deze groep studenten altijd door anderen veroorzaakt, of worden toegeschreven aan eenmalige incidenten. Hierbij gaat het dus met name om tekortkomingen in de dimensie 'omgaan met zichzelf' van professioneel gedrag.

Uit ervaring blijkt echter ook dat studenten tekortschieten binnen de andere dimensies van professioneel gedrag. Binnen het domein 'omgaan met taken/werk' betreft het bijvoorbeeld het zich houden aan afspraken, het laten zien van een actieve houding en het tonen van initiatieven. Binnen het domein 'omgaan met anderen' gaat het vaak om tekortkomingen op het gebied van het samenwerken met anderen en de bejegening. Ook valt op dat het vrijwel niet voorkomt dat er alleen sprake is van achterstanden in het domein van professioneel gedrag. Meestal zijn één of meerdere aspecten van kennis en vaardigheden (professioneel handelen) eveneens onvoldoende.

Ten aanzien van studenten die minder deficiënt zijn op het gebied van professioneel gedrag bestaan echter meer positieve ervaringen. Wanneer het professioneel gedrag in de eerste studiejaren regelmatig wordt beoordeeld en deze beoordeling primair plaatsvindt in het kader van het geven van feedback aan studenten over sterke en zwakke punten, worden sommige studenten gestimuleerd om actief iets te doen aan de geconstateerde zwakke punten. Dit uit zich dan ondermeer in een bezoek aan de studieadviseur of mentor, die om advies wordt gevraagd inzake het omgaan met zwakke punten in het professioneel functioneren.

\section{Omgaan met problematiek van studenten met onprofessioneel gedrag.}

Wanneer een student komt met een onvoldoende beoordeling van professioneel ge- 
drag, is het belangrijk om als begeleider na te gaan of er sprake is van een structureel of incidenteel probleem. Structurele problemen uiten zich logischerwijs vaker gedurende het onderwijstraject. Incidentele problemen kunnen het gevolg zijn van niet bij elkaar passende persoonlijkheden (incompatibilité des humeurs). In de regel blijkt dit snel genoeg uit de toelichting bij de melding, dan wel uit de rapportage van de student. In principe kan men in dat geval rustig afwachten en blijft het bij deze ene melding.

Eveneens is het belangrijk hoe de student op de onvoldoende beoordeling reflecteert, hoe de student zijn of haar eigen aandeel ziet, wat de oorzaken zijn volgens de student, wat de student ervan heeft geleerd en wat de student zou willen veranderen of verbeteren. Vervolgens kan er over de aanpak van deze veranderingen gepraat worden. Studenten met onvoldoende reflectief vermogen dienen eerst 'therapierijp' gemaakt te worden. Soms betekent dat afwachten tot de volgende negatieve beoordeling en hopen dat het de student duidelijker wordt hoe hij of zij overkomt bij anderen en wat er met hem of haar aan de hand is. Vervolgens dient de student bereid te zijn te veranderen.

Hoe er verder moet worden omgegaan met studenten inzake het professioneel functioneren is sterk afhankelijk van de wijze van implementatie van professioneel gedrag binnen het curriculum. Zo is het aantal beoordelingsmomenten, het soort beoordelingsmoment (tussentijdse of eindbeoordeling), de fase van de studie waarin de beoordelingsmomenten plaatsvinden en de onderwijsactiviteit waarbinnen het professioneel gedrag beoordeeld is, van grote invloed op de adviezen en de daaraan verbonden consequenties. Het zal duidelijk zijn dat een melding van een tutor in het eerste jaar betreffende een student die niets zegt tijdens een onder- wijsgroep in principe een andere lading heeft dan een melding van een onderwijscoördinator van een co-assistentschap interne geneeskunde die een student ongeschikt vindt voor het vak.

Zoals reeds eerder aangegeven, verdient het aanbeveling dat iemand de coördinatie van de zorg rondom de student op zich neemt. Het ligt voor de hand dat dit in eerste instantie diegene is die formeel ook verantwoordelijk was voor de begeleiding van de student. In de meeste faculteiten is dat de studieadviseur. De begeleider van de student heeft een aantal opties met betrekking tot de aanpak van het probleem.

De eerste optie is om de student zelf te begeleiden. De mogelijkheid en wenselijkheid hiervan zijn sterk afhankelijk van het soort probleem en de competentie van de begeleider. De minimale eis is dat de begeleider de vaardigheid bezit om het probleem en/of de problemen van de student zo helder mogelijk in kaart te brengen. Dit bepaalt immers de vervolgacties.

Tevens kan de student verwezen worden naar personen binnen de faculteit. Dit kunnen docenten zijn die de student de gelegenheid geven bepaalde vaardigheden op te doen en de mogelijkheid hebben de student hierbij ook extra te begeleiden. Bijvoorbeeld het geven van extra communicatietrainingen als daar een probleem ligt of de student mee laten lopen op de afdeling onder extra toezicht en begeleiding. Ook kan de student verwezen worden naar docenten die studenten mee kunnen laten lopen met reguliere onderwijsprogramma's van andere studiejaren om bepaalde elementen van professioneel gedrag die daar aan bod komen te oefenen. Het aanbod kan ook bestaan uit onderdelen van bestaande programma's.

Studenten kunnen ook verwezen worden naar hulpverleners buiten de faculteit maar binnen de universiteit. Bij verwijzingen naar functionarissen binnen de uni- 
versiteit neemt de studentendecaan vaak een belangrijke plaats in. Deze kan ondermeer bepalen of achterstanden opgelopen bij de studie, hetgeen bij serieuze problemen vaak het geval is, nog voor enigerlei vorm van compensatie in aanmerking komen op grond van universitaire regelgeving. De studentenpsycholoog is vanzelfsprekend ook een voorbeeld van iemand die binnen een universitaire setting een belangrijke rol kan vervullen inzake problematiek van professioneel gedrag. Een voordeel van deze functionaris is dat zorg als meer laagdrempelig wordt ervaren dan de psychologische hulpverleningsinstanties in de 'burgermaatschappij'. Ook is de zorg gratis en is de specifieke facultaire setting bij de hulpverleners vaak bekend. Veelal echter is de zorg in tijdsduur beperkt en zal bij ernstiger problematiek moeten worden doorverwezen naar bijvoorbeeld een RIAGG of een vrij gevestigde psycholoog. Ook een loopbaanadviseur kan een belangrijke rol spelen om studenten alternatieven te bieden qua studie. Alternatieven die mogelijk beter passen bij de geconstateerde sterke en zwakke punten van de studenten.

De vierde optie betreft een verwijzing naar personen die niet werkzaam zijn aan faculteit en universiteit, bijvoorbeeld een huisarts, geestelijk verzorger of psycholoog. Er dient bij de student te worden nagegaan of er ook andere belangrijke personen zijn in diens nabije omgeving waarnaar verwezen kan worden.

Gelet op de ervaring binnen faculteiten dat ernstige tekortkomingen op het gebied van professioneel gedrag vaak gepaard gaan met vragen en problemen op andere gebieden ligt een brede aanpak met het inschakelen van meerdere functionarissen voor de hand. Dit betekent dat in de praktijk vaak een combinatie van bovengenoemde opties wordt toegepast. Zo is het voorstelbaar dat een student met commmunicatieproblemen met patiënten deels (opnieuw) communicatietrainingen volgt in het reguliere onderwijsprogramma of dat de student wordt verwezen naar een studentenpsycholoog, terwijl hij/zij bovendien regelmatig wordt opgeroepen door de studieadviseur om de aanpak en het effect ervan te evalueren. Eveneens wordt er - met toestemming van de student - op aangedrongen te zorgen voor extra begeleiding op dat punt door de onderwijscoördinator van een volgend co-assistentschap.

\section{Specifieke aandachtspunten bij de begeleiding}

Als eerste dient te worden bepaald wie de begeleiding coördineert van studenten met tekortkomingen op het gebied van professioneel gedrag. Binnen de huidige facultaire structuur is dit meestal de studieadviseur. Dit moet ook duidelijk aan studenten en medewerkers worden medegedeeld.

Wanneer professioneel gedrag regulier beoordeeld wordt, is duidelijk vastgelegd hoe dergelijke beoordelingen procedureel worden afgehandeld. Het dient echter voor medewerkers evenzeer duidelijk te zijn waar ze met incidentele meldingen van problemen rondom professioneel gedrag terecht kunnen. Het is belangrijk dat faculteiten hier aandacht aan besteden.

Wanneer studenten begeleid worden, dient men zich goed te realiseren wat de context is waarbinnen een beoordeling gegeven wordt. Zoals reeds eerder aangegeven hangen eventuele acties af van het aantal beoordelingsmomenten, het soort beoordelingsmoment (betreft het een tussentijdse of eindbeoordeling), de fase van de studie waarin de beoordelingsmomenten plaatsvinden en de onderwijsactiviteit waarbinnen het professioneel gedrag beoordeeld is. Zo zal een onvoldoende beoordeling van professioneel gedrag op 
basis van het functioneren in een practicumgroep in het tweede jaar in de meeste gevallen tot andere acties leiden dan een onvoldoende eindoordeel over professioneel gedrag tijdens de co-assistentschappen.

Gelet op de problematiek die zich voordoet bij ernstige vormen van niet professioneel functioneren dient een begeleider van de student altijd duidelijke schriftelijke afspraken te maken met de betreffende student, zodat hierover in een later stadium geen misverstand kan bestaan. Het opbouwen van een zorgvuldig dossier over de student is voor de begeleiding essentieel. Uiteraard is dit dossier vertrouwelijk en alleen ter inzage van studieadviseur en student. Gedurende de periode dat de problematiek speelt, dient het contact met de student in ieder geval in stand te worden gehouden. Het contact houden met andere betrokkenen zoals een examencommissie is mede bepalend voor een afgewogen beleid ten aanzien van deze ingewikkelde problematiek.

Een complicerende factor bij het oplossen van problemen is dat de student niet verplicht kan worden gebruik te maken van de diensten en adviezen van de begeleider. Dit geldt (uiteraard) ook voor eventuele diensten die andere professionele hulpverleners kunnen aanbieden.

\section{Ten slotte}

De toegenomen belangstelling voor het evalueren van professioneel gedrag zal ook consequenties hebben voor het studiebegeleidingssysteem aan de faculteiten. Het zal het systeem niet zozeer in kwantitatieve zin belasten (aantal studenten) maar wel in kwalitatieve zin (bepaalde studenten kosten veel meer tijd).

Tevens dient geanticipeerd te worden op hoe men omgaat met dergelijke problematiek. Wie is waarvoor verantwoordelijk en wat kan ieders rol zijn bij dergelijke problematiek. Hierbij dient men zowel de universitaire diensten (studentenpsychologen, studentendecanen, adviseurs loopbaan en beroep, et cetera) als medewerkers binnen een faculteit uitdrukkelijk te betrekken. Verder is een goede dossieropbouw noodzakelijk alsmede regelmatig overleg met de examencommissie. Afstemming in een vroeg stadium van mogelijkheden en beperkingen van ieders rol en deskundigheid binnen en buiten de faculteit zal onnodige vertraging in het aanbod van zorg naar de student zoveel mogelijk voorkomen.

\section{Literatuur}

1. Projectteam Consilium Abeundi. Professioneel Gedrag; Onderwijs, toetsing, begeleiding, regelgeving. Utrecht; juli 2002.

2. Beoordeling van de Algemene Klinische Competentie. Advies van de Werkgroep Consilium Abeundi van het DMW (VSNU). Utrecht; juni 2000.

3. Luijk SJ van, Santen-Hoeufft M van, Hillen HFP, Smeets JGE. Het beoordelen van professioneel gedrag bij studenten en artsen. Tijdschrift voor Medisch Onderwijs 2000; 19(5):163-71.

4. Luijk SJ van, Smeets JGE, Smits JFM, Wolfhagen HAP, Perquin MLF. Beoordeling en begeleiding van professioneel gedrag tijdens de opleiding geneeskunde. Bulletin Medisch Onderwijs 1999; 18:58-65

5. Papadakis M, Osborn E, Cooke M, Healy K. A strategy for the detection and evaluation of unprofessional behavior in medical students. Acad Med 1999;74(9):980-90.

6. Papadakis M, Loeser H., Healy K. Early detection and evaluation of professionalism deficiencies in medical students: One school's approach. Acad Med 2001;76(11):1100-6.

De auteurs:

Dr. S.J. van Luijk, drs. M.L.F. Perquin en dr. G. Tans zijn allen (parttime) studieadviseurs aan de Faculteit der Geneeskunde van de Universiteit Maastricht.

Correspondentieadres:

Dr. S.J. van Luijk, Universitair docent, Capaciteitsgroep O\&O, Postbus 616, 6200 MD Maastricht, tel.: 043-3881131,S.vanLuijk@educ.unimaas.nl. 


\section{Summary}

Introduction: The increasing emphasis on professional conduct in medical education necessitates the availability of counselling for students with deficiencies in this area. Professional conduct comprises the professional's behaviour with regard to assignments/work, others and him/herself.

The role of the academic advisor: It should be very clear to whom students can turn for advice. The academic advisor should reconcile the occasionally opposed interests of students and educational organization.

Students with deficiencies in professional conduct: Deficiencies identified in the literature include: failure to take responsibility and keep appointments, lack of initiative, failure to collaborate, inability to deal constructively with criticism and communicate with patients. The students concerned are often unable to reflect on their personal conduct. Co-existing deficiencies in knowledge and skills are common. Early detection can promote effective action.

Dealing with deficiencies in professional conduct: The academic advisor can take action him/herself or seek help inside or outside the university. Coordination by one person is essential as is continuing contact with those involved. Specific points of attention: It should be clear who is responsible for counselling and guidance. The appropriate action depends on the stage in the curriculum when problems arise. Records of the guidance process are essential.

In conclusion: Medical schools should anticipate an increased need to provide guidance to students with professionalism deficiencies. This requires a protocol for counselling and referral. Delays in offering appropriate guidance to students can be prevented by timely identification of the possibilities and limitations of the roles and expertise of all actors involved. (Luijk SJ van, Perquin MLF, Tans G. How to guide students with professionalism deficiencies. Dutch Journal of Medical Education 2002;21(5):228-235.) 